\title{
A Model For Predicting Depression in Victims of Rape
}

\author{
Cheryl Regehr, MSW, PhD, Glenn Regehr, PhD, and \\ John Bradford, MB, ChB, FRCP
}

This article proposes a model for understanding the factors contributing to longstanding depression in women who have been raped. A path analysis of data obtained from 71 women who had been raped revealed that women with generalized beliefs that they could not control events in their lives were more likely to attribute responsibility for their rape to permanent intrapsychic factors and were more likely to be depressed. Women who perceived that they had higher levels of internal control tended to have higher levels of education, were more likely to be employed, and were less likely to be depressed more than one year after having been raped. Childhood sexual abuse was not associated with internal control or attributions of causality or depression in this analysis. Implications for the determination of prognosis and treatment recommendations in civil litigation assessments are discussed.

Forensic mental health practitioners are increasingly asked to assess the damages to victims of sexual assault who are seeking financial compensation for the devastating effects of rape. These effects include depression and symptoms of posttraumatic stress disorder. ${ }^{1,2}$ In addition to documenting current levels of distress, we are also often asked to comment on long-term prognosis and possible treatment outcomes. This article seeks to develop a model for understanding fac-

Dr. Cheryl Regehr is affiliated with Wilfrid Laurier University, Waterloo; Dr. Glenn Regehr with the University of Toronto, Toronto; and Dr. Bradford with the University of Ottawa, Ottawa, Ontario, Canada. This research was generously funded by the Social Sciences and Humanities Research Council of Canada. This paper was presented at the 28th Annual Meeting of the American Academy of Psychiatry and the Law, October 1997, Denver, CO. Address correspondence to: Cheryl Regehr, PhD, Wilfrid Laurier University, Waterloo, Ontario, N2L 3C5 Canada. tors contributing to long-standing depression in women who have been raped in an effort to assist with the determination of prognosis and treatment recommendations.

Depressive symptoms are commonly reported in longitudinal studies of women who have been raped. Initial reactions to sexual assault include sleep and eating disturbances, fatigue, suicidal ideation, and feelings of guilt, worthlessness, and hopelessness. ${ }^{3}$ Reported rates of depression in women during the first four weeks following a rape experience range from 68 percent $^{4}$ to 75 percent. ${ }^{5}$ These initial high levels of distress have been found to diminish to normal levels in the majority of women within the first few months postrape. ${ }^{5-7}$ For many women, however, residual problems persist. In a study of 
130 rape victims 1 to 2.5 years postassault, half of the women continued to fear being alone, and three-quarters reported continued suspiciousness of others, as well as additional problems such as selfimposed restrictions on daily life, depression, and sexual problems. ${ }^{8}$ Ellis et al. $^{9}$ report in their study that rape victims remained significantly more depressed, had higher ratings of family distress, tension, fatigue, anhedonia, and substance abuse than the control group one year postrape. Kilpatrick et $a l .,{ }^{10}$ in a random community sample, found that 19 percent of rape victims had attempted suicide compared with 2.2 percent of nonvictims and that 44 percent of rape victims reported serious suicidal ideation. Burnham et al. ${ }^{11}$ also found that a history of sexual assault increased the risk of major depressive episodes 2.4-fold.

It has been repeatedly observed in clinical practice and in qualitative research that victim self-blame is related to postrape depressive symptoms. ${ }^{1,12-15}$ This was most clearly demonstrated in studies by Frazier ${ }^{16,17}$ and Meyer and Taylor, ${ }^{18}$ who found that attributions of self-blame associated with rape were significantly associated with depression during the acute posttrauma phase. In contrast, victims who place the blame for the assault on societal factors experience a more positive postrape adjustment. ${ }^{16}$ Self-blame is interpreted as attributing causality for the assault to internal sources, such as the victim's behavior or character, rather than to external sources, such as a society that tolerates the abuse of women by perpetrators who are morally deviant. Such attributions may arise from an individual woman's previously held beliefs about herself or others. For instance, rape victims have been found to be more likely to blame themselves if they previously believed that they were immune to the risk of rape. ${ }^{19,20}$

While it seems clear that attributions of responsibility about the rape made by a victim are associated with posttrauma adjustment, ${ }^{16-18}$ it is important to note that the attributional style of the victim does not necessarily predict the onset of depression. These attributions of self-blame may in fact be manifestations of depression. $^{21,22}$ While Meyer and Taylor ${ }^{18}$ note that the self-blame in their sample may be part of a preexisting pattern of negative thinking and depression, they argue that other research showing that self-blame is not consistently associated with poorer adjustment after a traumatic event refutes that possibility. For instance, self-blame has been found to be adaptive among victims of severe accidents. ${ }^{23}$ However, in a longitudinal study on the relationship between attribution and adjustment following the death of a child, none of the attributional styles assessed (attributing blame to self, to someone else, to God, or to chance) predicted subsequent changes in psychological distress. ${ }^{24}$ These authors concluded that attributional style was a symptom of distress.

Other authors have attempted to differentiate between attributions that are situationally determined and those that are characterologic in origin. Seligman and Garber, ${ }^{25}$ in reformulating Seligman's ${ }^{26}$ learned helplessness model, suggested that the following dimensions of attributions are important: (1) internal versus 
external; (2) versus unstable; and (3) global versus specific. These varying types of attributions were seen to affect self-esteem and predict feelings of helplessness and depression. These authors proposed that of primary importance is the global-specific dimension, which determines the generality and chronicity of the problem. Janoff-Bulman ${ }^{27}$ suggested that directing blame at one's behavior may in fact be an adaptive strategy in the aftermath of rape, as this may increase a victim's sense of control over her recovery and reduce fears that she may be assaulted again in the future. She contrasts this with characterologic selfblame, which involves attributions to a relatively nonmodifiable source and is associated with a personal "deservingness" for the assault. Similarly, Foa et $a .^{28}$ propose that global, stable self-blame that generates to a sense of uncontrollability may increase the risk of trauma following sexual assault.

We propose that global, stable forms of self-blame are in fact due to locus of control, a preexisting personality factor. Locus of control can be used to define the patterned ways in which an individual perceives the sources of control over unforeseen stressors. ${ }^{29}$ Locus of control is seen to fall on a continuum between internal (all my successes and failures are the result of my own abilities and efforts) and external (everything that happens to me is a result of fate). The concept of locus of control is especially relevant for understanding responses to natural disasters due to the challenge of the victim's belief in a controllable and predictable world. Individuals who, in the face of disaster, manage to retain a belief that they can control outcomes have been found to manage the experience far more effectively than individuals who believe they were controlled by external forces. ${ }^{30}$ Accident victims with an internal locus of control were found to be better at coping with the hardships involved in the recuperative period when compared with victims with an external locus of control. ${ }^{31,32}$ Similarly, depression and suicidal ideation are consistently associated with an external locus of control. ${ }^{33,34}$ Perceived internal locus of control activates a person to solve problems, to limit undesirable consequences, and to avoid them in the future. Thus, a personality style that is reflected in meeting and solving problems as they arise reinforces an individual's sense of well being and supports the notion that one has power over the maintenance of well-being. 35

This study attempts to clarify the relationship between perceptions of control and long-term depression following rape. Perceptions of control are defined to encompass both perceptions specific to the rape experience (attributions of causality) and global perceptions (locus of control). While, previous research has suggested that attributions of causality are associated with traumatic reactions to sexual assault in the crisis period, ${ }^{16,18,19}$ to date this association has not been demonstrated with regard to longer-term recovery from rape.

The following model is proposed for predicting long-term depression in women who have been raped:

1. Compared with other attributions of causality for rape (external and internal, 
unstable), internal attributions of a stable nature will be the greatest predictor of depression in women who have been assaulted.

2. Locus of control is the characterologic base from which attributions of causality specific to rape emanate. These combined factors are hypothesized to predict depression.

3. Early childhood victimization experiences will be a predictor of locus of control.

4. Locus of control will have an interactional effect with demographic factors, including employment, education, and previous mental health problems, in predicting depression.

\section{Method}

This study included women who had been the victims of rape or attempted rape during their adult lives. Only women who had experienced the rape event a minimum of one year before the study were asked to participate. Subjects were drawn from several sources. Current and former clients of three sexual assault care centers were contacted by staff members and asked if they wished to participate. In addition, advertisements were placed on bulletin boards at three universities and at women's athletic and health centers. In all, 71 women completed and returned questionnaires. Nineteen of the women who completed the questionnaires had responded to advertisements, and 52 were recruited through sexual assault care centers. All subjects were provided with information as to the possible risks and benefits of participating in the study, and they provided signed consent with the returned questionnaires.

The questionnaire elicited demographic information as well as data on previous mental health problems and childhood sexual abuse experiences. One symptom status scale, the Beck Depression Inventory (BDI), ${ }^{36}$ was included to determine levels of persistent pathology in the study sample. Perceptions of control were measured by two scales, the Attributions of Causality for Rape Scale ${ }^{18}$ and the Internal Control Index (ICI). ${ }^{37}$

Measures. Beck Depression Inventory Originally developed in $1961,{ }^{36}$ the current BDI is a self-report scale that assesses the presence and severity of affective, cognitive, motivational, vegetative, and psychomotor components of depression. ${ }^{38}$ Each of the 21 items has four alternatives ranging from 0 (no depression) to 3 (severe depression) and yielding total scores in a range from 0 to 63 . Recommended ranges for quantifying the level of depression are 0 to 4 , none; 4 to 7 , mild; 8 to 15 , moderate, and $16+$, severe. $^{38}$ Initially standardized on 606 psychiatric inpatients and outpatients, the reported reliability coefficient is .86 . Test-retest reliability statistics are .48 for psychiatric patients (second testing after three weeks) and .74 for undergraduate students (second testing after three months).

Attributions of Causality for Rape Scale Meyer and Taylor ${ }^{18}$ devised a scale of 15 questions aimed at establishing the attributions of causality that women make regarding a sexual assault perpetrated against them. Women were asked to rate the degree to which each of 
the items explains the reason for their victimization on a five-point Likert scale from 0 (does not explain my assault at all) to 4 (completely explains why I was assaulted). A factor analysis of this scale, based on a sample of 58 women, resulted in three factors: poor judgment, societal factors, and victim type. Items on the societal subscale relate to external attributions of blame. The poor judgment subscale suggests internal attributions of an unstable nature. Finally, the victim type subscale measures the degree to which women believe the rape was caused by internal, stable factors. Reliability coefficents on the three subscales ranged from .64 to .79 (Cronbach's $\alpha$ ). The Meyer and Taylor ${ }^{18}$ study was replicated by Frazier $^{16}$ with a sample of 67 women who had been assaulted three days before participating in the study. A factor analysis was conducted with the sample in the present study, and the factor grouping confirmed those factor groupings discussed in the literature.

Internal Control Index Locus of control is a personality trait that defines the way a person perceives control over unforeseen stressors. ${ }^{29}$ The ICI is a 28 -item instrument designed to measure the degree of control and autonomy that an individual experiences. ${ }^{37}$ On each item, respondents are asked to rate on a five-point scale how often they feel or behave in a particular manner, from rarely (less than $10 \%$ of the time) to usually (more than $90 \%$ of the time). Total scores can range from 28 to 140 . The instrument has been tested on a variety of student populations including college students, university undergraduates, and continuing education students (total $n=1,365$ ). An internal consistency coefficient (Cronbach's $\alpha$ ) of .84 is reported. $^{37}$

\section{Results}

Respondents The mean age of the women in this sample was 29.1 , with an age range of 17 to 47 years. Seven percent of the women indicated that they had not completed high school, 51 percent indicated that high school was the highest level of education attained, and 42 percent had completed college or university. Thirty-nine percent of the women were employed full time. Twenty-one percent of the sample indicated that they had experienced mental health problems before the rape, including substance abuse, suicidal thoughts, and problems that required treatment with psychotropic medication. Forty-three percent indicated that they had been sexually abused at least once as a child, and 57 percent had been previously raped. The most recent rape had occurred an average of 4.6 years before the present study.

Attributions of Causality Previous research suggests that if a woman attributes causality for the rape to her own judgment or to herself as being a "victim type," she will exhibit high levels of traumatic symptomatology in the acute posttrauma phase, ${ }^{16,18}$ while women who attribute the rape to societal factors will have lower levels of distress. ${ }^{16}$ In the present study, there was a significant positive correlation (.52) between a woman viewing herself as a "victim type" and the level of depression. This correlation is predicted by the model that states that of specific attributions for rape, stable, in- 
Table 1

Correlational Matrix of Factors Included in the Model

\begin{tabular}{|c|c|c|c|c|c|c|}
\hline Beck Depression Inventory & 1.0 & & & & & \\
\hline Internal Control Index & $-.599^{\star}$ & 1.0 & & & & \\
\hline Victim type attributions & $.545^{\star}$ & $-.483^{\star}$ & 1.0 & & & \\
\hline Education & $-.531^{\star}$ & $.478^{\star}$ & $-.363^{\star \star}$ & 1.0 & & \\
\hline Employment & $-.343^{\star \star}$ & $.254^{\star \star}$ & -.126 & .154 & 1.0 & \\
\hline \multirow[t]{4}{*}{ Childhood sexual abuse } & $.254^{\star \star \star}$ & -.049 & .180 & -.023 & $-.322^{\star \star}$ & 1.0 \\
\hline & Beck & Internal & Victim & Education & Employment & Childhood \\
\hline & Depression & Control & Type & & & Sexual \\
\hline & Inventory & Index & Attributions & & & Abuse \\
\hline
\end{tabular}

${ }^{*}$ Coefficients more than twice their standard error at $p<.001$.

${ }^{\star \star}$ Coefficients more than twice their standard error at $p<.05$.

ternal attributions of causality would be the strongest predictor of long-term depression following assault. Contrary to the findings of Frazier ${ }^{16}$ however, there was also a significant positive correlation (.46) between attributing responsibility to societal factors and scores on the BDI, suggesting that stable, external attributions of blame are also associated with higher levels of depression. While at first glance this may appear to be contradictory, in fact both internal, stable attributions and external, stable attributions represent a sense of helplessness in controlling negative events. In contrast, the association between attributing causality for rape to poor judgment (internal, unstable factors) and BDI scores was not significant. (See Table 1 for correlations between all variables in the model.)

Locus of Control The ICI had a significant negative correlation with the BDI $(-.60)$, indicating that women with higher levels of internal control were less depressed. This is consistent with the research on other clinical and non-clinical populations.

Personal History and Assault Characteristics In general, research findings conclude that women with a previous history of either rape or childhood incest exhibit higher overall symptomatology following a subsequent sexual assault. ${ }^{17,39-42}$ In the current study, childhood sexual abuse (.25) and previous rape (.26) are both significantly associated with BDI scores. Contrary to our hypothesis, a history of childhood sexual abuse was not associated with scores on the ICI. Mannarino and Cohen ${ }^{43}$ similarly report no correlation between locus of control and the occurrence of sexual abuse in children. Previous studies have also found a correlation between previous mental health problems and postrape psychological adjustment. ${ }^{5,17,44}$ There was no significant correlation in the current study between level of emotional distress and previous mental health problems. Employment (-.34) and education $(-.53)$ were both negatively correlated with depression scores.

Multifactoral Explanations for Postrape Distress To generate a model describing the effects of life history/demographic variables and perceptions of control on the continuance of long-term depressive symptoms, a path analysis was 


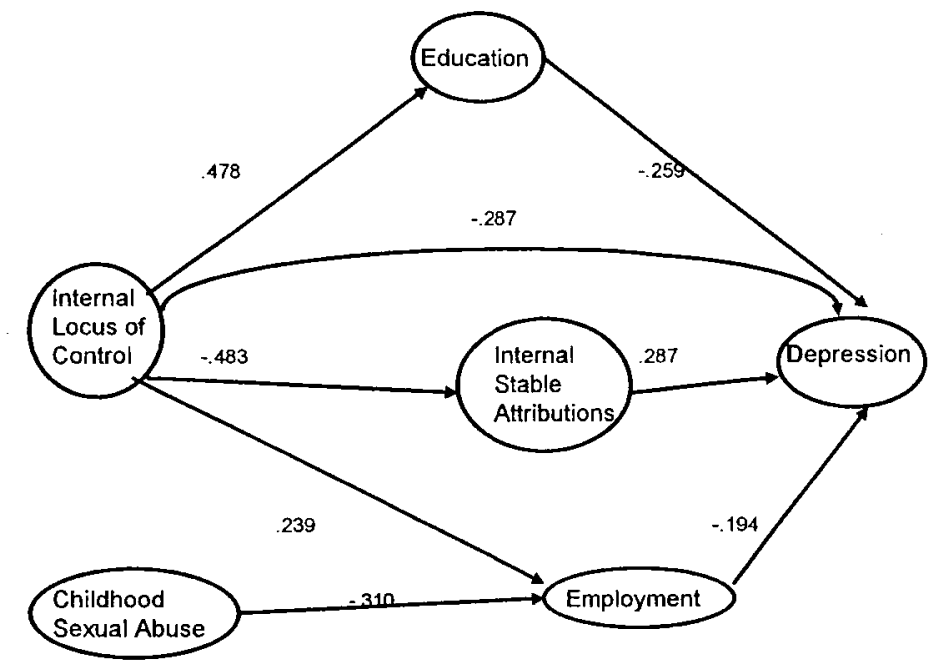

Figure 1. Path analysis model for predicting depression in women who have been raped.

conducted. Three personal history/demographic variables (previous childhood sexual abuse, education, and employment), the ICI, and the victim type subscale of the Attributions of Causality Scale were included in the model. The results of the analysis may be seen in Figure 1.

The ICI correlates directly with depression scores. Scores on the ICI also negatively correlated with scores on the victim type subscale of the Attributions of Causality for Rape scale and positively correlated with level of education and employment status. These factors in turn are correlated with depression. Childhood sexual assault does not predict scores on the ICI or the victim type subscale but does predict employment status.

\section{Discussion}

In this study, two of the subscales of the Attributions of Causality for Rape Scale, victim type and societal attribu- tions, were significantly associated with scores on the BDI in women who had been raped an average of 4.6 years earlier. The most significant association was between the victim type subscale and the depression scores, which confirms the hypothesis that internal attributions that are stable will be the best predictors of depression. The association between attributing causality for the rape to societal factors suggests that external attributions are also maladaptive to the recovery process. Each of these positions, feeling that one is a victim type and feeling that the world is a dangerous place that perpetuates violence against women, can be viewed as a victim stance. Such a stance suggests that the individual experiences a limited sense of power to control traumatic events in her life.

There was a significant negative correlation between scores on both the ICI and the BDI. Women who perceived that they had higher levels of control over the out- 
come of events in their lives had lower rates of depression more than six months after a rape. Conversely, women who perceived that they had lower levels of control had higher rates of depression. While the self-selection bias of this sample may have skewed the results, these findings, which associate feelings of power and control with levels of emotional distress, are validated by other parallel research findings. Previous research has demonstrated associations between locus of control and emotional distress in survivors of trauma. $^{31,32}$

In addition to the significant correlations between long-term depressive symptoms and perceptions of control, significant correlations were also found between four personal history/demographic variables and scores on the BDI. Previous histories of childhood sexual abuse and rape were both significantly associated with the BDI scores. Education and employment were significantly negatively correlated with BDI scores. Previous mental health problems were not associated with depression.

The path analysis sought to further differentiate the relative effects of global perceptions of control as measured by the ICI, internal/stable attributions of causality as measured by the victim type subscale of the Attributions of Causality for Rape Scale, education, employment, and childhood sexual assault. This analysis revealed that women with lower levels of internal control were more likely to view themselves as victim types and were more likely to be depressed. Women with higher levels of internal control tended to have higher levels of education, were more likely to be employed, and were less likely to be depressed more than one year postrape. Childhood sexual abuse was not associated with internal control or attributions of causality or depression in this analysis. However, sexual abuse does appear to influence depression postrape by virtue of the fact that women who were abused as children are less likely to be employed. In this analysis, global perceptions of control were the most important factor in predicting depression postrape.

Previous researchers have concluded that attributions of causality are important predictors of adjustment following rape. ${ }^{16,18}$ While negative attributions may lead to depression, a sizable body of research literature suggests that depression results in negative perceptions and outlook. 21, 22, 45, 46 That is, the depressed state may color the interpretation of events resulting in a belief that all factors-poor personal judgment, an unsafe society, and being a victim type-contributed to the occurrence of rape. We would suggest that a third factor may be at play in this association. That is, longstanding global perceptions of control (as measured by the ICI in this study) influence both attributions of causality and depression.

\section{Implications for Intervention}

These findings have significant implications for forensic practice both in terms of offering an opinion regarding prognosis and in making treatment recommendations. As with all other traumatic experiences, women who are raped have preexisting strengths and vulnerabilities that affect their responses to trauma. The 
results of this study suggest that women who have had life experiences that resulted in a global sense of powerlessness and a belief that their destiny is controlled by external events are more vulnerable to long-term depression following rape. This appraisal that they have limited control over their lives may lead to a belief system that suggests they were raped because they are a "victim type" and also contributes to lower levels of employment and education. These combined factors result in increased risk of long-term depression.

Much of the clinical literature on treatment of victims of sexual assault has focused on a crisis-oriented, psychoeducational model. The aim of the current model is to assist a woman to understand the nature of her disturbance, to understand that her reaction is normal, and to integrate her reaction into preexisting cognitive structures. Such an approach provides corrective information so that the rape event and its aftermath will not be distorted. For instance, explaining that posttraumatic stress disorder and depression are normal, temporary reactions to a horrific event, reinforcing previous coping, and reassuring women that they will be able to manage this crisis. Resick and Schnicke $^{47}$ report research findings that support the success of this type of treatment model with women who have been raped. In their work, however, they attempt to exclude women with histories of incest or with personality disorders, indicating that these two groups of women are less likely to benefit from this treatment approach.

Women who are suffering from long- term depression following sexual assault may have preexisting vulnerabilities that cause them to require a different approach. While the sexual assault experience may have led to the depression, the depression may equally be sustained by other long-term historical factors and personality characteristics. As such, it may be that traditional methods of treating depression, such as pharmacological intervention along with cognitive therapy, ${ }^{21,22}$ which focuses on global feelings of control, may be of greatest benefit to these women and may in fact lead to reduced distress over the sexual assault experience. The efficacy of these types of treatment for women who suffer from longterm depression subsequent to a rape experience is an avenue for further research.

\section{References}

1. Burgess A, Holstrum L: Rape trauma syndrome. Am J Psychiatry 131:981-86, 1974

2. Steketee G, Foa E: Rape victims: post-traumatic stress responses and their treatment. J Anxiety Disord 1:69-86, 1987

3. Calhoun K, Atkeson B: Treatment of Rape Victims: Facilitating Psychosocial Adjustment. Toronto: Pergamon Press, 1991

4. Frank E, Turner S, Duffy B: Depressive symptoms in rape victims. J Affect Disord 1:269-77, 1979

5. Atkeson B, Calhoun K, Resick P, Ellis E: Victims of rape: repeated assessment of depressive symptoms. J Consult Clin Psychol 50:96-102, 1982

6. Kilpatrick D, Veronen L, Resick P: The aftermath of rape: recent empirical findings. Am $\mathbf{J}$ Orthopsychiatry 49:658-69, 1979

7. Murphy S: Mediating effects of intrapersonal and social support on mental health 1 and 3 years after a natural disaster. $\mathbf{J}$ Trauma Stress 1:155-72, 1988

8. Nadelson C, Notman M, Zackson H, Gornick $\mathrm{J}$ : A follow-up study of rape victims. Am J Psychiatry 139:1266-9, 1982 
9. Ellis E, Atkeson B, Calhoun K: An assessment of long-term reaction to rape. J Abnorm Psychol 90:263-6, 1981

10. Kilpatrick D, Best C, Veronen L, Amick A, Villeponteaux L, Ruff G: Mental health correlates of criminal victimization: a random community survey. J Consult Clin Psychol 53:866-73, 1985

11. Burnham M, Stein J, Golding J, et al: Sexual assault and mental disorders in a community population. J Consult Clin Psychol 56:84350,1988

12. Libow J, Doty D: An exploratory approach to self-blame and self-derogation by rape victims. Am J Orthopsychiatry 49:670-8, 1979

13. Moscarello R: Psychological management of victims of sexual assault. Can J Psychiatry 35:25-30, 1990

14. Nadelson C: Consequences of rape: clinical and treatment aspects. Psychother Psychosom 51:187-92, 1990

15. Rabkin $\mathbf{J}$ : The epidemiology of forcible rape. Am J Otthopsychiatry 49:634-46, 1979

16. Frazier P: Victim attributions and post-rape trauma. J Pers Soc Psychol 59:298-304, 1990

17. Frazier P: Self-blame as a mediator of postrape depressive symptoms. J Soc Clin Psychol 10:47-57, 1991

18. Meyer CB, Taylor SE: Adjustment of rape. J Pers Soc Psychol 50:1226-34, 1986

19. Cascardi M, Riggs D, Hearst-Ikeda D, Foa E: Objective ratings of assault safety as predictors of PTSD. J Interpers Violence 11:65-78, 1996

20. Veronen LJ, Kilpatrick DG: Rape: a precursor to change, in Life Span Developmental Psychology: Normative Life Events. Edited by Callahan E, McCluskey D. New York: Academic Press, 1983, pp 167-91

21. Beck A: Depression: Clinical, Experimental, and Theoretical Aspects. New York: Hoeber Press, 1967

22. Beck A, Rush J, Shaw B, Emery G: Cognitive Therapy of Depression. New York: Guilford Press, 1979

23. Bulman R, Wortman C: Attributions of blame and coping in the "real world": severe accident victims react to their lot. J Pers Soc Psychol 35:351-83, 1977

24. Downey G, Silver R, Wortman C: Reconsidering the attribution-adjustment relation following a major negative event: coping with the loss of a child. J Pers Soc Psychol 59:92540,1972

25. Seligman M, Garber J: Human Helplessness. Toronto: Academic Press, 1980
26. Seligman M: Helplessness: On Depression, Development and Death. San Francisco: Freeman, 1975

27. Janoff-Bulman R: Characterological versus behavioral self-blame: inquiries into depression and rape. J Pers Soc Psychol 37:17981809,1979

28. Foa E, Steketee G, Olasov-Rothbaum B: Behavioral/cognitive conceptualizations of posttraumatic stress disorder. Behav Ther 20:15576,1989

29. Rotter J: Some problems and misconceptions related to the construct of internal versus external control of reinforcement. $J$ Consult Clin Psychol 43:56-67, 1975

30. Gibbs M: Factors in the victim that mediate between disaster and psychopathology: a review. J Trauma Stress 2:489-514, 1989

31. Silver R, Wortman C: Coping with undesirable life events, in Human Helplessness: Theory and Application. Edited by Garber J, Seligman M. Toronto: Academic Press, 1980

32. Silver R, Wortman C, Klos D: Cognitions, affect and behavior following uncontrollable outcomes: a response to current human helplessness research. J Pers 50:480-514, 1982

33. Lefcourt H: Personality and locus of control, in Human Helplessness: Theory and Applications. Edited by Garber J, Seligman M. Toronto: Academic Press, 1980

34. Mirowsky J, Ross C: Control or defense?: depression and the sense of control over good and bad outcomes. J Health Soc Behav 31:7186,1990

35. Bandura A, Adams N, Beyer J: Cognitive processes mediating behavioral change. J Pers Soc Psychol 35:125-39, 1977

36. Beck AT, Ward CH, Mendelson M, Mock J, Erbaugh $\mathrm{J}$ : An inventory for measuring depression. Arch Gen Psychiatry 4:53-63, 1961

37. Duttweiler P: The Internal Control Index: a newly developed measure of locus of control. Educ Psychol Meas 44:209-21, 1984

38. Beck AT, Beamesderfer A: Assessment of depression: the depression inventory, in Psychological Measurements in Psychopharmacology. Edited by Pichot P. Paris: Karger, Basel, 1974, pp 151-69

39. Cohen L, Roth S: The psychological aftermath of rape: long-term effects and individual differences in recovery. J Soc Clin Psychol 5:525-s34, 1987

40. Ellenson G: Horror, rage, and defenses in the symptoms of female sexual abuse survivors. Soc Casework 589-96:1989 


\section{Predicting Depression in Victims of Rape}

41. Lindberg FH, Distad LJ: Post-traumatic stress disorders in women who experienced childhood incest. Child Abuse Neg1 9:329-34, 1985

42. Follette V, Polusny M, Bechtle A, Naugle A: Cumulative trauma: the impact of child sexual abuse, adult sexual assault, and spousal abuse. J Trauma Stress, 17:25-35, 1996

43. Mannarino A, Cohen J: Abuse-related attributions and perceptions, general attributions, and locus of control in sexually abused girls. J Interpers Violence 11:162-80, 1996

44. Frank E, Turner S, Stewart B, Jacob M, West
D: Past psychiatric symptoms and the response to sexual assault. Compr Psychiatry 22:479-87, 1981

45. Brewin C: Cognitive Foundations of Clinical Psychology. Hillsdale, NJ: Erlbaum, 1989

46. Engle R, DeRubeis R: The role of cognition in depression, in Psychopathology and Cognition. Edited by Dobson K, Kedall P. San Diego: Academic Press, 1993

47. Resick P, Schnicke M: Cognitive Processing Therapy for Rape Victims. Newbury Park, NJ: Sage Publications, 1993 